
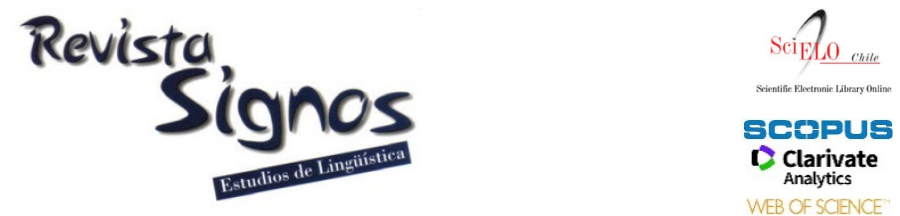

\title{
Toward a framework for heritage learner service learning in languages for specific purposes* $^{*}$
}

\section{Hacia un marco para al aprendizaje servicio de aprendices de berencia en lenguas con fines específicos}

\author{
Diana M. Ruggiero \\ UNIVERSITY OF MEMPHIS \\ UNITED STATES \\ dmrggero@memphis.edu
}

Recibido: 21-IV-2018 / Aceptado: 15-X-2018

DOI: $10.4067 /$ S0718-09342019000300931

\begin{abstract}
Building on previous research and the author's own experience, this article concerns service learning design for heritage learners in languages for specific purposes. Heritage learner prior knowledge of and identification with the culture and language of study distinguishes them from L2 learners. As a result, the distinct learning needs of heritage learners pose a challenge to language educators attempting to integrate service learning, whether in languages for specific purposes or otherwise. Yet despite the need to rethink service learning in languages for specific purposes to meet the needs of this growing student population, few studies on the subject exist. Through a survey of the relevant extant literature, the author identifies the known benefits of service learning for heritage learners and considers the implications of heritage learner needs in the design of languages for specific purposes service learning projects. Best practices identified in the literature and through the author's own experience are then used to develop a service learning framework specific to heritage learners in languages for specific purposes. Specifically, best practices observed in the literature include project and learning objectives that build on, strengthen, and expand five key areas: heritage learner previous knowledge of and identification with the culture and language; critical awareness of social and cultural issues relevant to heritage learner identity; cultural competence; heritage learner professional career goals; and heritage learner knowledge of specialized written and spoken language skills in formal and informal registers. The author concludes that an asset-based approach, evident in existing heritage learner service learning projects, is key to maximizing service learning benefits for heritage learners. Rethinking service learning in this way is significant in developing cultural and communicative competence among heritage learners in languages for specific purposes.
\end{abstract}

Key Words: Languages for specific purposes, community service learning, heritage learner, language pedagogy, service learning design. 


\section{Resumen}

Basado en investigaciones anteriores y la misma experiencia del autor, este artículo trata del diseño del aprendizaje- servicio para estudiantes de herencia en el área de lenguajes para fines específicos. El conocimiento previo y la identificación con la cultura y el idioma de estudio del estudiante de herencia lo distingue de los estudiantes de L2. Como resultado, las distintas necesidades de aprendizaje de los estudiantes de herencia representan un desafío para los profesores de idiomas que intentan integrar el aprendizaje-servicio, ya sea en idiomas para fines específicos o de otro tipo. Sin embargo, a pesar de la necesidad de repensar el aprendizaje- servicio en idiomas con fines específicos para satisfacer las necesidades de esta creciente población estudiantil, existen pocos estudios sobre el tema. A través de una revisión extensa de la relevante literatura existente, el autor identifica los conocidos beneficios del aprendizaje- servicio para estudiantes de herencia y considera las implicaciones de las necesidades del estudiante de herencia en el diseño de idiomas para proyectos del aprendizaje- servicio con fines específicos. Las mejores prácticas identificadas en la literatura y la propia experiencia del autor se utilizan para desarrollar un marco del aprendizaje- servicio específico para los estudiantes de herencia en idiomas para fines específicos. Específicamente, las mejores prácticas observadas en la literatura incluyen objetivos de proyectos y aprendizaje que se basan, fortalecen y expanden en cinco áreas claves: conocimiento previo del estudiantes de herencia e identificación con la cultura y el idioma; conciencia crítica de las cuestiones sociales y culturales relevantes para la identidad del estudiante de herencia; competencia cultural; objetivos profesionales de la carrera del estudiante de herencia; y el conocimiento de los estudiantes de herencia de habilidades especializadas en lenguaje oral y escrito en registros formales e informales. $\mathrm{El}$ autor concluye que un enfoque basado en los valores, evidente en los proyectos existentes del aprendizaje- servicio de estudiantes de herencia, es clave para maximizar los beneficios del aprendizaje- servicio para los estudiantes de herencia. Repensar el aprendizaje- servicio de esta manera es significativo en el desarrollo de la competencia cultural y comunicativa entre los estudiantes de herencia en idiomas para fines específicos.

Palabras Clave: Lenguas con fines específicos, aprendizaje-servicio en la comunidad, hablante de herencia, enseñanza de lenguas, diseño de aprendizaje-servicio.

\section{INTRODUCTION}

This article concerns service learning (SL) for heritage learners (HLs) in languages for specific purposes (LSP). Specifically, it surveys existing studies of HL SL projects and builds on the author's own experience with SL in LSP for the purposes of developing a framework for HL SL project design in LSP. The need for this article is based on an evident gap in the research on this subject. Indeed, for over a decade, scholarship in LSP has shown the value and benefits of SL in advancing the objectives of LSP and the twenty-first century agendas of professional language organizations such as the Modern Language Association and the American Council on the Teaching of Foreign Languages (e.g., Nelson \& Scott, 2008; Abbott \& Lear, 2010; Lafford, 2012; Lear, 2012; Sánchez-López, 2013; Sánchez-López, Long \& Lafford, 2017). Yet, few studies have considered the learning needs and potential contributions of HLs in SL and even fewer consider the implications of HL involvement in SL projects 
specifically designed to meet LSP learning objectives. An examination of SL design and objectives as they relate to HLs is crucial in developing an LSP curriculum responsive to the needs of this population and the global marketplace.

The term heritage learner, which also appears in the academic literature as heritage language learner (HLL), refers to students pursuing the study of a language that constitutes a part of their cultural heritage (see Beaudrie \& Fairclough, 2012). As the growing literature on HLs point out (e.g., Beaudrie \& Ducar, 2005; Beaudrie, Ducar \& Potowski, 2014; Leeman, 2015; Zapata, 2018), HLs exhibit varying degrees of proficiency in the language in question yet positively relate to the language as a part of their cultural heritage and identity. For this reason, much of the academic literature on HL pedagogy focuses on the unique learning needs of HLs in connection to identity and advocates an approach to language learning that foregrounds culture and issues of relevance to HLs (e.g., Wong \& Xiao, 2010; Carreira \& Kagan, 2011; Beaudrie et al., 2014; Wu, Lee \& Lung, 2014; Zapata, 2018). Given that much of the literature in this area relates to Spanish HLs (SHLs) and considering the author's own area of expertise, this article focuses primarily on this population.

Drawing on recent literature and on the author's own experience in the field, a review of recent approaches to SL curriculum design will lead to developing a framework that is responsive to the needs of HLs, specifically in LSP educational settings. The following literature review outlines the known benefits of SL for HLs and common design elements in HL SL, in LSP and otherwise, and identifies best practices that can be used to develop a framework for HL SL in LSP. The second part of the article builds on the extant literature and the author's own experience to address practical issues in SL design for HLs in LSP. Among the questions addressed along the way are the following: How does SL benefit HLs? How is the SL experience unique for this population? How might the benefits and experience of SL for HLs inform project design in an LSP educational context? Other questions for further reflection in HL SL design in LSP are included in the appendix. Identifying best practices in project design for LSP is significant in preparing and supporting HLs in their desire to serve in an increasingly diverse yet seemingly fractured global society.

\section{Literature review}

\subsection{Benefits of SL for HLs}

The benefits of SL for L2 students, LSP learning objectives, and community partners are by now well outlined in the literature. In providing students with realworld learning opportunities, students gain experience in career paths of potential interest, use their language skills in service to local target-language communities, and establish connections between concepts and issues discussed in the classroom and the lived experiences of people in the world outside of academia (Sánchez-López, 2013). 
In the process, students acquire specialized language skills, learn about the needs of and issues facing local communities and community partners, build professional networks, and are exposed to linguistic and cultural diversity within the target language (e.g., Hellebrandt \& Varona, 1999; Barreneche, 2011; Pérez-Llantada \& Watson, 2011; Zapata, 2011; Falce-Robinson \& Strother, 2012; Lafford, 2012; Lear, 2012; Ruggiero, 2015). At the same time, community partners receive student support and additional resources in meeting service objectives and local community needs (see Lear \& Abbott, 2009; Hellebrandt \& Jorge, 2013; Lear \& Sánchez, 2013). In addition, among other student-learning benefits, studies report gains in student confidence in language use as well as increased motivation for continued study in the target language (e.g., Falce-Robinson \& Strother, 2012; Barreneche \& Ramos-Flores, 2013; Petrov, 2013; Medina \& Gordon, 2014). They also report advances in linguistic gains (Bloom, 2008; Hale, 1999; Olazagasti-Segovia, 2004; Salgado-Robles, 2014; Weldon \& Trautmann, 2003), intercultural sensitivity (McBride, 2010; Ruggiero, 2016; Derby, LeLoup, Rasmussen \& de Souza, 2017), and self-esteem (e.g., McBride, 2010; Petrov, 2013; Ruggiero, 2016; Pascual y Cabo, Prada \& Pereira, 2017).

Recent scholarship explores how HLs specifically benefit from and contribute to SL. Perhaps the most significant observed benefit of SL for HLs specifically relates to identity formation. Indeed, SL can be a transformative experience for HLs (e.g., McBride, 2010; Petrov, 2013; Rodríguez-Sabater, 2015; Isabelli \& Muse, 2016; Ruggiero, 2017). The bilingual and bicultural identity of HLs places them in a unique position relative to local heritage-language communities. HLs' relationship to their heritage language and cultural identity are heightened in SL projects in which students directly engage with local community members. National, regional, generational, and other differences in vocabulary, grammar, and language use as well as socioeconomic disparities and variations in cultural values, beliefs, and community needs force HLs to confront their own identity and relationship to their heritage language and culture (Leeman, Rabin \& Román-Mendoza, 2011; Petrov, 2013; Pascual y Cabo et al., 2017). When allowed to reflect on these differences through assignments and class discussion, HLs show tremendous growth in their awareness of cultural heterogeneity, the relationship between language and culture, issues of social justice, and of their own identity as a result (e.g., Martínez \& Schwartz, 2012; Petrov, 2013; Pereira, 2015). Just as with L2 learners, many HLs recognize their value in the community as mentors and role models. Furthermore, when working with children, HLs become especially cognizant of the added value their cultural identity brings to their service in the community (Petrov, 2013; Ruggiero, 2017). The impact of SL on HL self-esteem, identity, and on motivation for continued language study in service to the community takes on even greater significance for HLs as a result.

Indeed, the literature confirms that it can have a transformative effect on HLs in terms of their self-esteem and sociocultural identity (McBride, 2010; Petrov, 2013; 
Rodríguez-Sabater, 2015; Ruggiero, 2017). This much is due to increased selfawareness during SL, as HLs reflect on the social and professional value of their bilingual and bicultural identity during the course of a project (e.g., McBride, 2010; Ruggiero, 2017). As a result, SL builds HL self-esteem, instilling in them a sense of agency tied to their language and cultural heritage. Though longitudinal studies are needed to assess the lasting impact of such transformative experiences, increased selfesteem and a positive outlook on one's sociocultural identity may have a significant impact on future HL learning, professional career choices, and interest and investment in the well-being of the local communities with which they identify, which are multiple given their bicultural identity. This much is bolstered by studies relating to the development of intercultural sensitivity that show how attitudes concerning cultural difference build over time with continued intercultural contact (Bennett, 1993; Deardorff \& Edwards, 2013).

\subsection{SL design for HLs}

A great diversity of SL projects is evident in the growing literature on HLs. In general, projects range from small-scale individual or small group student led projects with multiple community partners (e.g., Petrov, 2013; Pereira, 2015; DuBord \& Kimball, 2016; King de Ramírez, 2017; Llombart-Huesca \& Pulido, 2017; Pascual \& Cabo et al., 2017) to large-scale initiatives coordinated between a whole class and a single community partner (e.g., Martínez \& Schwartz, 2012; King de Ramírez 2016; MacGregor-Mendoza \& Moreno, 2016; Ruggiero, 2017). In both instances, projects may involve either direct or indirect student engagement with the community (e.g., Martínez \& Schwartz, 2012; King de Ramírez, 2016; Ruggiero, 2017). When students are required to directly interact with community members, projects often take on the form of teaching or tutoring (e.g., McBride, 2010; Leeman et al., 2011; RodríguezSabater, 2015), translating and interpreting (e.g., Martínez \& Schwartz, 2012), or helping community partners execute existing service projects (e.g., Tilley-Lubbs, 2004; Martínez \& Schwartz, 2012). In the case of indirect student contact with community members, projects often involve translation or other services utilizing student communication, professional, and technological skills (e.g., King de Ramírez, 2016). In contrast, larger scale projects often place students in a collaborative relationship with community partners and the community and are designed in conjunction with the needs of all interested parties (e.g., Martínez \& Schwartz, 2012; King de Ramírez, 2016; Ruggiero, 2017). Regardless of the type of project and student-community interface, technology is increasingly being incorporated to reach and extend service to the community (e.g., King de Ramírez, 2016).

As to be expected, the rich diversity of SL projects noted above reflects a variety of needs, concerns, and constraints, including those of community partners, instructors, students, and educational institutions. Foremost among the limitations informing SL 
design are access to local heritage-language communities, community partner needs, the focus and learning objectives of the course, and the language proficiency and technical skills of the students in question (Abbott \& Lear, 2010). Student career interests, training in related professional skills, and preparation for community service, for example, may be limiting factors in the choice of community partners and in project design for an LSP SL project (Lear \& Abbott, 2009; Lear \& Sánchez, 2013). Yet another factor is the number of hours students may be required to commit to SL. Though the focus of a given course may specifically be on SL, most if not all institutions impose a maximum limit on the number of hours students may be required to devote to service in the community. Though such rules are necessary to avoid abuse of student time, they nonetheless restrict project design choices and may perhaps impact the quality of student engagement with the community. Given these limitations, it is not surprising that many existing SL projects take on the form of teaching or tutoring, translating, writing, volunteer work, and internships.

Despite the diversity and limitations of existing HL SL projects, common design elements are evident. Among them are a defined number of contact hours with the community or project, a means of keeping track of student hours, strategic use of class time to facilitate and maximize student engagement with the project and community, the use of pre- and post-surveys for assessment and research purposes, community partner and sometimes community member feedback in the form of surveys or interviews likewise for assessment or research, and the use of reflective assignments, such as journals, essays, and portfolios. In all instances, the use of class time for introducing, discussing, and reflecting upon key theories and concepts related to the SL objectives and experience is observed. When projects involve an entire class engaged with a single community partner (e.g., Martínez \& Schwartz, 2012; King de Ramírez, 2016; Ruggiero, 2017), meetings with community partners and/or with students and community partners toward the assessment and refinement of project goals and objectives during the SL experience are also noted.

Though the above elements also reflect current conventions in L2 SL project design, in HL initiatives, they differ in terms of the ways in which they reflect and emphasize the distinct learning objectives and needs of HLs. Specifically, SL projects for this population foreground objectives related to identity formation, awareness of cultural and linguistic differences, social justice, and leadership or mentorship, and community building (e.g., Leeman et al., 2011; Petrov, 2013; Isabelli \& Muse, 2016; MacGregor-Mendoza \& Moreno, 2016). While language acquisition and other linguistic concerns likewise factor into the design of HL SL projects (e.g., Pereira, 2015; Tocaimaza-Hatch \& Walls, 2016; Llombart-Huesca \& Pulido, 2017), they are de-emphasized or, rather, recontextualized within a broader social and cultural framework that seeks to maximize the identity-related benefits of SL for HLs. This is 
also the case when SL is used to further HL professional language development (e.g., Martínez, 2010).

\subsection{SL design for HLs in LSP}

As King de Ramírez notes (2017), few studies address HLs in LSP, let alone SL. The three known studies that do address this topic (e.g., Martínez \& Schwartz, 2012; King de Ramírez, 2016, 2017), however, provide a foundation from which to develop best practices in SL design for this population specifically in this educational context. Together, these studies reinforce the sociocultural and linguistic benefits of SL for HLs while highlighting different approaches to the integration and structure of SL within the LSP curriculum.

Notably, presents two contrasting models of SL projects in two separate studies $(2016,2017)$. In one, she incorporates a community-building campus radio project for students in an advanced course on Spanish for the professions (King de Ramírez, 2016). Structured as a single project involving the entire class, its design reflects an asset-based approach to HL education as well as LSP specific and sociocultural related objectives. Specifically, the project builds on student knowledge of national Spanish radio programming in the development of Spanish radio content geared toward the underrepresented Latin@ community on campus. HL administered campus surveys helped identify topics of interest to the campus Latin@ population, broadening HL awareness of relevant social and cultural issues and reinforcing the need for and value of such a space and platform for addressingLatin@ concerns. In terms of structure, the project included a three-week training period followed by the production of the radio programs. Project participants met regularly with the instructor and solicited community feedback on the content. In addition, students were required to complete a pre- and post-course survey and bi-monthly reflection writing assignments. Relating to course specific LSP objectives, students developed professional language and other skills in the area of media and were exposed to new career opportunities. As King de Ramírez notes, students self-reported an increase in their self-confidence related to the development of their language skills and to their newfound sense of belonging on campus as a result of the SL project.

In yet another study, King de Ramírez (2017) highlights the potential value of internship-type SL models for HLs in LSP. Emphasizing the need to better connect HL awareness of the ways in which classroom learning connects with marketplace needs and expectations, King de Ramírez notes that professional community internships (PCIs), as opposed to standard community based professional SL, are well suited to tailoring learning outcomes to student goals (King de Ramírez, 2017). In this study, King de Ramírez observed reflection assignments and survey results for 7 HLs enrolled in a PCI course as part of a Spanish for the professions minor. Students completed 135 hours of service as well as a pre-internship questionnaire and post 
internship survey. In addition, students completed bi-monthly self-reflections and met weekly with community mentors. PCIs ranged from social work and community advocacy to communications and mass media and matched the respective career goals of the students involved. The author notes that though service activities varied across the different PCIs, community partner expectations of HLs were consistent and included "oral communication skills, translation skills, social networking abilities, and immigration knowledge" (King de Ramírez, 2017: 61). Based on the survey results and student self-reflections, this author found that HLs experienced an increase in awareness of sociocultural issues and learned to bridge cultural differences with Hispanic co-workers and community members. In addition, students reported gains in their linguistic skills (i.e., specialized vocabulary and written and spoken communication skills).

In contrast, Martínez and Schwartz (2012) present a participatory model of SL for HLs in a medical Spanish minor that attracts students from within and outside of the Spanish major. Integrated into the third semester of a four-course sequence, the SL component pairs students with a local health clinic serving uninsured and low-income community members, many of whom are Spanish speaking. Likewise adopting an asset-based approached to HL education, it is designed to build on and strengthen HL cultural knowledge and linguistic abilities while exposing them to cultural differences and sociocultural issues of relevance. At the same time, active community partner participation in the design, implementation, and assessment of the course syllabi, project, and outcomes ensure that both student and community benefits are maximized. The project itself consists of 15 contact hours at the clinic. Working with the health and nutrition education department of the clinic, students perform various tasks from translating materials to participating in individual and small group classes on diabetes for Spanish speaking patients. As a part of the project assessment, students are given performance evaluations, take a reflective questionnaire, and give an end of project presentation before clinic staff who have served as student mentors. In their study, Martínez and Schwartz found that HLs participating in this project reported gains in HL awareness of and appreciation for language variation, motivation for language maintenance, and in professional linguistic abilities.

The respective projects of King de Ramírez and Martínez and Schwartz highlight five related points already evident in the emerging literature on HLs and SL. Specifically, the notion that SL design in LSP build on, strengthen, and expand the following:

- HL knowledge of and previous experience with the language and culture in question (King de Ramírez, 2017; MacGregor-Mendoza \& Moreno, 2016; Martínez \& Schwartz, 2012).

- Critical awareness of social and cultural issues relevant to HL identity (Leeman et al., 2011; Martínez \& Schwartz, 2012; Petrov, 2013; Trujillo, 2009). 
- Cultural competence (King de Ramírez, 2016, 2017; Llombart-Huesca \& Pulido, 2017; Martínez \& Schwartz, 2012; Ruggiero, 2017).

- HL professional career goals (Isabelli \& Muse, 2016; King de Ramírez, 2016, 2017; Martínez \& Schwartz, 2012).

- HL knowledge of specialized written and spoken language skills in formal and informal registers (King de Ramírez, 2017; Martínez \& Schwartz, 2012).

The final two points draw attention to the field's emphasis on pre-professional training and preparation (King de Ramírez, 2017) while the first three reflect a broader concern with developing HL sociocultural identity, empowering HLs and local communities of the target language, career networking, developing professional language skills, and pre-professional training. Beyond the question of identity and the need to develop professional language skills, however, both King de Ramírez and Martínez and Schwartz stress the need for students to become aware of the socioeconomic and sociocultural realities and issues impacting the local communities they will serve. They also stress the need to teach skills in navigating cultural differences in the workplace. For King de Ramírez and Martínez and Schwartz, this means direct engagement with diverse populations in the target language, community partner mentorship, and participatory, or collaborative, engagement with community partners in the design and assessment of SL projects. Though few, the above studies provide trends pointing toward an emergence of best practices in SL design for HLs in LSP. As a means of orienting educators interested in integrating SL for this population in the field, the following provides considerations and models based on the existing literature and the author's own experience.

\section{Practical considerations in SL design for HLs in LSP}

Though SL design and specific project and learning objectives will necessarily differ in accordance with the course, community partner(s), and type of project, the points gleaned from the extant literature noted above are nonetheless useful in developing a SL framework for HLs in LSP. Questions for consideration in the design of SL projects are provided in the Appendix for instructional purposes.

\subsection{SL project objectives}

As emphasized in the literature, an asset-based approach to SL will build on HL background and experiences to maximize their service and learning potential (King de Ramírez, 2017). In the context of LSP, this may mean a focus on building specific language and cultural competency as well as professional skills related to the language abilities, cultural background, and career interests of individual students as in the PCI model (Ibid.). In the process, HLs will not only strengthen the language and cultural competency skills needed to succeed in such a professional environment, but they will also become aware of language differences and of the significance of the heritage 
language and its various uses in workplace communication. SL projects involving interpreting and translation serve such learning objectives (e.g., Martínez \& Schwartz, 2012).

In conjunction with the second and third guiding points (raising critical awareness and cultural competence), an asset-based approach may likewise mean building HL language, cultural, and professional competency within a SL project that challenges student assumptions and expands broader understandings of issues related to language, culture, identity, and social justice. The radio service learning project designed by King de Ramírez (2016), for example, exposed students to cultural differences among the campus Latin@ community and to the need for advocacy of Latin@ issues on campus. Similarly, Martínez and Schwartz (2012) exposed HLs to cultural differences in the workplace and to disparities in the healthcare system impacting the local Hispanic population. In such cases, students may not only become aware of linguistic differences in the workplace, they may reflect on their own familiarity with the language and on their own relationship relative to the community in question. This level of reflection, informed by critical readings and discussions of the relevant social and linguistic topics in class, can lead to profound student insights regarding identity and language use as well as cultural and social differences.

Regardless of whether critical pedagogy is foregrounded, an asset-based approach allows for the integration of the final two guiding points relating to HL professional preparation. As King de Ramírez notes (2017), SL in LSP must link classroom learning with marketplace needs and expectations. She goes on to argue that this includes an emphasis not only on the acquisition of professional vocabulary, but also on the preparation and practical experience in issues specific to the community and profession, navigation of cultural differences in the workplace, and spoken and written bilingual skills in formal and informal registers (King de Ramírez, 2017). This author (2016, 2017) accomplishes this in the tailoring of projects to the career goals and learning needs of the students, assessed through the use of surveys. Similarly, Martínez and Schwartz (2012) accomplish this, in part, through the focus of the course - as an integral component of a medical Spanish minor-and in exposing students to cultural differences within the local Spanish speaking community. As a result, HLs in the medical Spanish project are able to build on their cultural background and language skills in fulfilling the project objectives. At the same time, student cultural awareness and communicative competence are strengthened and expanded within a professional context.

The development of professional language skills is a necessary component of a HL course in LSP. Language learning objectives, however, may be approached as a means of broadening HL awareness of a range of identity and social issues. Doing so can help strengthen HL cultural sensitivity and competence (Ruggiero, 2017), which, in turn, can have a significant impact on HL self-esteem and identity formation (Petrov, 
2013; King de Ramírez, 2016; Ruggiero, 2017). As the research suggests (e.g., Martínez \& Schwartz, 2012; Petrov, 2013; King de Ramírez, 2016, 2017; Ruggiero, 2017), such transformative experiences may help HLs gain the confidence they need to navigate cultural and social differences in the workplace and community. In this way, an assetbased approach focused on the development of cultural as well as linguistic competence within a specific, professional context can fulfill all five guiding points of the suggested SL framework.

\subsection{SL design}

Once partners and learning objectives are identified, a needs assessment may help determine the viability and type of SL project. For example, King de Ramírez (2016) involved students in the administration of surveys soliciting issues and topics of interest among campus and community Latin@s in her radio SL project. The students used the survey results to develop radio program content. In the process, students were exposed to the cultural diversity of the campus Latin@ population, relevant issues, and to social justice needs. Similarly, Martínez and Schwartz (2012) directly involved community partners in the design of the project and accompanying course syllabi. In this way, they ensured the project fulfilled both community partner and student learning objectives.

From there, how SL projects are structured depends on multiple factors, including institutional constraints on SL hours, community partner availability, and the type of student-community interface involved. As a bridge between academia and the community, SL implies a relationship between the classroom and the project itself. In many projects with direct student-community interface, class time is divided between traditional classroom learning and SL (e.g., Martínez \& Schwartz, 2012; King de Ramírez, 2016; Ruggiero, 2017). King de Ramírez (2016), for example, integrates the radio project directly into her course syllabus and calendar, providing a highly structured SL experience for her students. Similarly, the author builds contact hours into the course calendar, evenly dividing classroom and service learning. Such a structure is useful in meeting student scheduling and availability issues and in avoiding overburdening students with contact hours outside of class. This may not be possible, however, in PCI models (e.g., King de Ramírez, 2017). Further research is needed to determine whether the structure of SL models impacts SL benefits and learning outcomes.

Whether integrated into the course calendar and syllabi, instructors must determine the relationship between classroom learning and SL. As evident in much of the HL SL literature, the broader social and cultural concerns informing HL learning objectives frame the classroom experience (e.g., Leeman et al., 2011). Within an LSP specific course, the emphasis may vary but the overall connection between language, culture, and society (including the workplace) prevails as noted in the five guiding points 
above. For example, if incorporating a PCI model, students experiencing different professional environments will need to use class time to reflect on broader issues relating to LSP, perhaps LSP pedagogy, and/or linguistic, cultural, and social issues that will help them to better contextualize their respective experiences (e.g., Martínez \& Schwartz, 2012; King de Ramírez, 2017). In contrast, a group SL project with a single community partner offers instructors an opportunity to tailor specific lessons and discussions to the project in question (e.g., King de Ramírez, 2016; Ruggiero, 2017). In this case, students can make direct linkages that they are able to reflect upon individually and as a class. In both instances, the author advocates the use of class time to address relevant social and cultural issues by making use of invited speakers, audio-visual material, reading materials, and class writing and discussion exercises that allow students to raise questions and critically reflect on their SL experience (see Ruggiero, 2017). The questionnaire and mentorship model used by Martínez and Schwartz (2012), for example, allows students to reflect on their experiences. The use of community feedback and regular reflection writing assignments in King de Ramírez' radio and PCI projects similarly allow space for reflection $(2016,2017)$.

As noted above, assessments commonly used in SL can be a significant means of engaging HLs in critical reflection. Tied to learning, project, and research objectives, they range from surveys (pre and post) and interviews, to periodic written assignments, reflection journals, and portfolio projects. Surveys and interviews seek to establish baselines and parameters from which to better assess student SL experiences, student learning and growth in communicative and cultural competence, community impact, and community partner perceptions of student engagement with the project (e.g., Martínez \& Schwartz, 2012; King de Ramírez, 2016, 2017; Ruggiero, 2017). King de Ramírez (2017), for example, structures her PCI pre-project survey and bi-monthly writing assignments such as to better define student career goals and learning objectives and focus student reflections along specific learning outcomes. Her post project survey likewise encourages student reflection of learning outcomes through questions that measure strength of agreement using a Likert scale (i.e., strongly agree, agree, disagree, etc.). The author likewise uses similar survey instruments and reflection writing prompts in SL (see Ruggiero, 2017). In addition, the author encourages the use of digital media (i.e., digital storytelling) as an alternative or complementary form of reflection (Ibid.). The incorporation of digital media may address issues in student preparedness for reflection writing (see McBride, 2010), as student visual observations may yield unconscious student perceptions relating to their HL experience (Ruggiero, 2016).

It is important to note that it is in relation to the reflection assignments, whether journals, questionnaires, or portfolios, that scholars note the connections HLs make between their SL experience and their growing awareness of social, cultural, and identity issues (e.g., McBride, 2010; Petrov, 2013; King de Ramírez, 2016; Ruggiero, 
2017). Given the tendency to subsume language-learning objectives for HLs in LSP within a broader social and cultural framework, reflection journals are less used as a means of assessing writing proficiency as for identifying areas of development in student thinking relative issues of language, culture, identity, and difference (e.g., King de Ramírez, 2016, 2017; Ruggiero, 2017). This suggests that special attention should be given to tailoring reflection assignments to HL needs and learning outcomes.

\section{CONCLUSIONS}

As the studies surveyed in this article show, SL benefits HLs in LSP on the professional and personal level. Professionally, students acquire language and communicative competence skills specific to a given professional context and community and receive training and mentorship in career and service opportunities that value and have need for bilingual skills and bicultural knowledge (e.g., Martínez \& Schwartz, 2012; King de Ramírez, 2016, 2017). Personally, HLs see an increase in selfesteem and awareness of a host of related social and cultural issues relevant to identity formation and language use and maintenance in the professions and community (Ibid.). HLs thus emerge from SL experiences in LSP with a greater sense of who they are personally and of what they have to offer professionally that is unique to the global marketplace and local communities as a result. How might the benefits and experience of SL for HLs inform project design in an LSP educational context?

Given these known benefits, SL in LSP differs for HLs in terms of the overall emphasis learning and project objectives place on issues of identity and the development of cultural competence and critical awareness. Martínez and Schwartz (2012) as well as King de Ramírez (2016, 2017) and Ruggiero (2017), for example, all seek to strengthen HL identity, in part, by exposing students to cultural and language differences, socioeconomic realities, and issues of social justice relevant to the local Hispanic community and the specific context of the project itself. This much is in keeping with current trends in HL education and speaks to current socio-political dynamics specifically facing SHLs in the United States.

Though the acquisition of profession specific vocabulary and language skills are equally important objectives, they are approached in the literature more as a means of broadening HL awareness of a range of sociocultural and sociolinguistic issues and are treated almost as a by-product of the SL experience itself. Indeed, as King de Ramírez (2017) and Martínez and Schwartz (2012) show, when students apply their language skills in professional contexts that demand real-world marketplace expectations of bilingual employees, students not only report gains in professional language skills, but higher self-esteem as well. For this reason, King de Ramírez concludes that LSP SL projects may be suitable alternatives to language specific courses for HLs (King de Ramírez, 2017). Regardless, an asset-based approach to SL, as advocated in the 
literature, allows for projects that build on existing cultural knowledge and language abilities and that strengthen and expand cultural and communicative competence within specific contexts.

Taking into consideration best practices evident in the existing studies, this article concludes that SL design considerations for HLs in LSP must reflect the unique learning needs of this student population. As the guiding points of the framework outlined above highlight, HL awareness of their own cultural identity and subjective positioning to the communities they serve is key in developing HL cultural and communicative competence in the workplace and community. This holds true regardless of the type of project or choice of community partner, as evident in the existing models (e.g., Martínez \& Schwartz, 2012; King de Ramírez, 2016, 2017). Yet, as King de Ramírez (2017) notes, SL must also match student learning with actual workplace expectations placed on bilingual employees. Following Martínez and Schwartz (2012), this means placing HLs in situations that challenge and expand HL cultural knowledge and language abilities. In both instances, however, it is clear that instructors attempting to design SL projects for HLs in LSP must first and foremost take into consideration and leverage the unique bicultural and bilingual identity of this population.

\section{REFERENCES}

Abbott, A. \& Lear, D. (2010). The connections goal area in Spanish community service learning: Possibilities and limitations. Foreign Language Annals, 43, 231 245.

Barreneche, G. (2011). Language learners as teachers: Integrating service learning and the advanced language course. Hispania, 94(1), 103-120.

Barreneche, G. \& Ramos-Flores, H. (2013). Integrated or isolated experiences?: Considering the case for service-learning in the Spanish language curriculum. Hispania, 96(2), 215-228.

Bennett, M. J. (1993). Towards ethnorelativism: A developmental model of intercultural sensitivity. In R. M. Paige (Ed.), Education for the intercultural experience (2nd ed.) (pp. 21-71). Yarmouth, ME: Intercultural Press.

Beaudrie, S. \& Ducar, C. (2005). Beginning level university heritage language programs: Creating a space for all heritage language learners. Heritage Language Journal, 3(1), 1-26.

Beaudrie, S. M. \& Fairclough, M. (2012). Introduction: Spanish as a heritage language in the United States. In S. M. Beaudrie \& M. Fairclough (Eds.), Spanish as a Heritage Language in the United States: The State of the Field (pp. 1-17). Washington, DC: Georgetown University Press. 
Beaudrie, S. M., Ducar, C. \& Potowski, K. (2014). Heritage Language Teaching: Research and Practice. New York, NY: McGraw Hill.

Bloom, M. (2008). From the classroom to the community: Building cultural awareness in first semester Spanish. Language, Culture, and Language Curriculum, 21(2), 103119.

Carreira, M. \& Kagan, O. (2011). The results of the National Heritage Language Survey: Implications for teaching, curriculum design, and professional development. Foreign Language Annals, 44(1), 40-64.

Derby, L., LeLoup, J., Rasmussen, J. \& de Souza, S. (2017). Developing intercultural competence and leadership through LSP curricula. In M. Long (Ed.), Languages for Specific Purposes: Trends in Curriculum Development (pp. 73-86). Washington, DC: Georgetown University Press.

Deardorff, D. \& Edwards, K. (2013). Framing and assessing students' intercultural competence in service learning. In P. Clayton, R. Bringle \& J. Hatcher (Eds.), Research on Service Learning: Conceptual Frameworks and Assessment: Communities, Institutions, and Partnerships (pp. 157-183). Sterling, VA: Stylus Pub.

DuBord, E. \& Kimball, E. (2016). Cross-language community engagement: Assessing the strengths of heritage learners. Heritage Language Journal, 13(3), 298-330.

Falce-Robinson, J. \& Strother, D. (2012). Language proficiency and civic engagement: The incorporation of meaningful service-learning projects in Spanish language courses. Interdisciplinary Humanities, 29(3), 73-87.

Hale, A. (1999). Service-learning and Spanish: A missing link. In J. Hellebrandt \& L. T. Varona, Construyendo Puentes (Building Bridges): Concepts and Models for ServiceLearning in Spanish (pp. 9-31). Washington, DC: American Association for Higher Education.

Hellebrandt, J. \& Jorge, E. (2013). The scholarship of community engagement: Advancing partnerships in Spanish and Portuguese. Hispania, 96(2), 203-214.

Hellebrandt, J. \& Varona, L. T. (1999). Construyendo Puentes (Building Bridges): Concepts and Models of Service-Learning in Spanish. Washington, DC: American Association for Higher Education.

Isabelli, C. \& Muse, S. (2016). Service-learning in the Latino community: The impact on Spanish heritage language students and the community. Heritage Language Journal, 13(3), 331-353. 
King de Ramírez, C. (2016). Creating campus communities for Latin@s through service-learning: Heritage learners' broadcast university Spanish-Language radio. Heritage Language Journal, 13(3), 382-404.

King de Ramírez, C. (2017). Preparing students for the workplace: Heritage learners' experience in professional community internships. In M. Long (Ed.), Languages for Specific Purposes: Trends in Curriculum Development (pp. 55-71). Washington, DC: Georgetown University Press.

Lafford, B. (2012). Language for specific purposes in the United States in a global context: Commentary on Grosse and Voght (1991) revisited. The Modern Language Journal, 96, 1-27.

Lear, D. (2012). Language for specific purposes curriculum creation and implementation in the service to the U. S. community. The Modern Language Journal, 96, 158-172.

Lear, D. \& Abbott, A. (2009). Aligning expectations for mutually beneficial community service-learning: The case of Spanish language proficiency, cultural knowledge, and professional skills. Hispania, 92(2), 312-323.

Lear, D. \& Sánchez, A. (2013). Sustained engagement with a single community partner. Hispania, 96(2), 238-251.

Leeman, J. (2015). Heritage language education and identity in the United States. Annual Review of Applied Linguistics, 35, 100-119.

Leeman, J., Rabin, L. \& Román-Mendoza, E. (2011). Critical pedagogy beyond the classroom walls: Community service-learning and Spanish heritage language education. Heritage Language Journal, 8(3), 1-22.

Llombart-Huesca, A. \& Pulido, A. (2017). Who needs linguistics? Service-learning and linguistics for Spanish heritage language learners. Hispania, 100(3), 348-360.

MacGregor-Mendoza, P. \& Moreno, G. (2016). Connecting Spanish heritage language students with the community through service-learning. Heritage Language Journal, 13(3), 405-433.

Martínez, G. (2010). Medical Spanish for heritage learners: A prescription to improve the health of Spanish-speaking communities. In S. River-Mills \& J. A. Trujillo (Eds.), Building Communities and Making Connections (pp. 2-15). Newcastle upon Tyne, UK: Cambridge Scholars Pub.

Martínez, G. \& Schwartz, A. (2012). Elevating 'low' language for high stakes: A case for critical, community-based learning in a medical Spanish for heritage learners program. Heritage Language Journal, 9(2), 37-49. 
McBride, K. (2010). Reciprocity in service learning: Intercultural competence through SLA studies. In B. Dupuy \& L. R. Waugh (Eds.), Proceedings of Intercultural Competence Conference (pp. 235-261). Tucson, AZ: Center for Education Resources in Culture, Language, and Literacy.

Medina, A. \& Gordon, L. (2014). Service learning, phonemic perception, and learner motivation: A quantitative study. Foreign Language Annals, 47(2), 357-371.

Nelson, A. \& Scott, J. (2008). Spanish in the university curriculum: A successful model for community-based service-learning. Hispania, 91(2), 446-460.

Olazagasti-Segovia, E. (2004). Second language acquisition, academic service learning, and learners' transformation. In J. Hellebrandt, J. Arries \& L. Varona (Eds.), Juntos: Community Partnerships in Spanish and Portuguese (pp. 5-16). Boston, MA: Thomas/Heinle.

Pascual y Cabo, D., Prada, J. \& Pereira, K. L. (2017). Effects of community servicelearning on heritage language learners' attitudes toward their language and culture. Foreign Language Annals, 50(1), 71-83.

Pereira, K. L. (2015). Developing critical language awareness via service-learning for Spanish heritage speakers. Heritage Language Journal, 12(2), 159-185.

Pérez-Llantada, C. \& Watson, M. (Eds.). (2011). Specialized Languages in the Global Village: A Multi-perspective Approach. Newcastle Upon Tyne, UK: Cambridge Scholars Pub.

Petrov, L. A. (2013). A pilot study of service-learning in a Spanish heritage speaker course: Community engagement identity and language in the Chicago area. Hispania, 96(2), 310-327.

Rodríguez-Sabater, S. (2015). Service learning and intercultural competence in the Spanish as a second language classroom. Southern Journal of Linguistics, 39(1), 1 23.

Ruggiero, D. (2015). Bridging the community and institution gap: A sample course with civic engagement and language for specific purposes combined. Journal of Languages for Specific Purposes, 1(2), 35-48.

Ruggiero, D. (2016). The creating communities, engaged scholarship project (CruCES): Findings of a study on intercultural sensitivity and community service learning. In M. F. Litzler, L. J. García \& M. C. Tejedor (Eds.), Beyond the Universe of Languages for Specific Purposes (pp. 59-64). Alcalá de Henares, Spain: Universidad de Alcalá. 
Ruggiero, D. (2017). The CruCES project: A consideration of service learning and intercultural sensitivity among heritage learners. Revista de Lenguas para Fines Especificos, 23(1), 45-62.

Salgado-Robles, F. (2014). Desarrollo de la competencia estratégica oral en español como segunda lengua mediante el Aprendizaje-Servicio en el Bluegrass de Mexington. Estudios de Lingüística Aplicada, 59, 125-148.

Sánchez-López, L. (2013). Service-learning course design for languages for specific purposes programs. Hispania, 96(2), 383-396.

Sánchez-López, L., Long, M. \& Lafford, B. (2017). New directions in LSP research in US higher education. In M. Long (Ed.), Languages for Specific Purposes: Trends in Curriculum Development (pp. 13-34). Washington, DC: Georgetown University Press.

Tilley-Lubbs, G. (2004). Service-learning and foreign-language teacher education. Hispania, 87(1), 132-134.

Tocaimaza-Hatch, C. C. \& Walls, L. C. (2016). Service-learning as a means of vocabulary learning for second language and heritage language learners of Spanish. Hispania, 99(4), 650-665.

Trujillo, J. A. (2009). Con todos: Using learning communities to promote intellectual and social engagement in the Spanish curriculum. In M. Lacorte \& J. Leeman (Eds.), Español en Estados Unidos y Otros Contextos de Contacto: Sociolingüística, Ideologia y Pedagogía (pp. 369-395). Madrid, Spain: Iberoamericana.

Weldon, A. \& Trautmann, G. (2003). Spanish and service-learning: Pedagogy and Praxis. Hispania, 86(3), 574-585.

Wong, K. F. \& Xiao, Y. (2010). Diversity and difference: Identity issues of Chinese heritage language learners from dialect backgrounds. Heritage Language Journal, $7(2), 153-187$.

Wu, M., Lee, K. \& Lung, G. (2014). Heritage language education investment among Asian American middle schoolers: Insights from a charter school. Language and Education, 28(1), 19-33.

Zapata, G. (2011). The effects of community service learning projects on L2 learners' cultural understanding. Hispania, 94(1), 86-102.

Zapata, G. (2018). A match made in heaven: An introduction to learning by design and its role in heritage language education. In G. Zapata \& M. Lacorte (Eds.), Multiliteracies Pedagogy and Language Learning: Teaching Spanish to Heritage Speakers (pp. 1-26). New York, NY: Palgrave Macmillan. 


\section{APPENDIX}

\section{Appendix A: Questions for consideration in SL design for HLs in LSP}

- What local organizations, institutions, and businesses serve the local population of the target language (for or not-for profit)?

- What are the needs of the local population of the target language?

- How do local organizations, institutions, and businesses serve those needs?

- What are the needs of local organizations, institutions, and businesses?

- How might HLs support local community partners in meeting their service objectives and otherwise serve the needs of the target language community?

- What types of SL projects are viable given local needs and opportunities?

- What possibilities exist for virtual SL projects?

- How might community partners and the SL project(s) identified serve the learning objectives of the course?

- How do community partners and the SL project(s) identified build on the linguistic strengths and cultural knowledge of HLs? Are HLs exposed to cultural and linguistic differences in the heritage language? Are HLs exposed to issues of social, cultural, and/or political relevance? Are HLs able to apply and build on their existing language skills? Are HLs given opportunities to develop pre-professional and pre-service skills (language related or otherwise) related to their career interests? Are HLs exposed to new or different professional and service job opportunities in which they can apply their language and cultural competence skills and knowledge?

- Do SL project assessments allow for reflection and critical reflection?

- Is the SL project integrated into the course?

- Does traditional classroom learning, in its content and delivery, prepare, support, and reinforce student skills, knowledge, and learning in relation to their SL project and course objectives?

- Are SL assessments aligned with the learning and project objectives?

\section{*ACKNOWLEDGEMENTS}

I wish to thank the editor of this issue, Dr. Francisco Salgado-Robles, and the reviewers for their constructive feedback and encouragement. I also want to thank my colleagues and students at The University of Memphis and my peers and mentors in WLSP and CSL who have contributed to my formation as a scholar and to the development of my research. I also want to acknowledge my husband and son for their steadfast companionship. 